\title{
A Simulink Model for Transmission Line Fault Detection
}

\author{
Aaron Don M. Africa, Benjamin Emmanuel Uy, Bianca Clarisse Tan \\ Department of Electronics and Communications Engineering \\ De La Salle University, Manila \\ 2401 Taft Ave., Malate, Manila 1004, \\ Philippines, aaron.africa@dlsu.edu.ph
}

\begin{abstract}
As cities throughout the world continue to develop, more and more transmission lines are utilized to be able to deliver electrical power for varying uses. Transmission lines hold a great responsibility in delivering power. Like all things, faults and interference can be created by foreign objects, obstructions, and natural calamities. Due to the importance of transmission lines, it is important to be able to detect faults in the lines to be able to minimize losses in power and revenue. Through this study, the software MATLAB will be utilized to successfully locate faults in transmission lines through various simulations. This study will attempt a simulation of a fault line detection method in Matlab. The researchers will utilize Matlab's toolboxes and Simulink to emulate a transmission line with a fault that will then be detected. The idea is to create a simulation model as a basis for future studies. Future studies will then be able to test other methods by building on the model created in this study. If their method is proven to be doable and effective, it could prove to be not only a more convenient method compared to direct circuit analysis but it could also be a more cost-efficient alternative for transmission line fault location.
\end{abstract}

Key words: Transmission Line, Fault Detection, Matlab, Simulink, Line to line fault, the line to ground fault.

\section{INTRODUCTION}

Transmission lines can experience various conditions and situations that could cause faults. Some of the conditions and situations transmission lines experience can be weather-related, material degradation, animal-caused damage, or outside object-caused damage [1]. Faults would then cause problems in the transmission line network. Typically, the transmission service could be downed. But there have been cases where faults have even caused large fires. Therefore, faults have the capability of causing severe environmental and structural harm.

To combat the fault problem, numerous studies creating various fault detection methods emerged. These various fault detection methods range from traveling wave-based methods [2], algorithmic methods [3,4,5], locus-based methods [6], terminal impedance-based methods [7], thyristor-based methods [8,9], relay-based methods [10], neural network and deep learning methods $[11,12,13,14]$, to Mathematical Morphology methods. These studies set out to investigate possible models of fault detection that overcome concerns of the inefficiencies previously established methods.

The typical means of analyzing the effectiveness of a fault detection method being studied is through the use of simulations. The simulations are performed using a variety of software developed to simulate electric power systems. The simulations use data and mathematical models to generate the possible outcomes as they take into consideration any possible variable defined by the researchers.

For this study, the researchers seek to emulate the process of simulating a fault detection method using Matlab and Simulink. Two programs are dedicated to mathematical calculations and simulations. The study will delve into the process of using the software, explain the various functions and commands used, and provide an understanding of how the two software can simulate a transmission line fault detection method and provide useful feedback to the researcher.

Therefore, this study will serve three functions: (1) This study will provide a background on transmission lines and transmission line fault detection. (2) This study will explore some literature on recent fault detection methods. (3) This study will serve as an introduction to the process transmission line fault detection simulation using Matlab and Simulink by showing how to model a transmission line system and how to explore fault detection within the model.

\section{BACKGROUND OF THE STUDY}

$80 \%$ of disturbances in transmission lines are caused by undetected faults. Because faults may occur due to various environmental factors such as natural calamities, techniques must be employed to ensure that power is continuous in the system. Continuous power in the system is important because as faults continue to occur without being accounted for, power quality continues to degrade over transmission lines. With this, fast and accurate detection is required to be able to ensure stability, performance, and efficiency [15]. As transmission networks consist of numerous lines, fault location using fault detectors are extremely costly. With this, it is important to find different ways to be able to find efficient means to detect 
fault through available techniques such as traveling--wave-based fault location and impedance-based method while integrating these into algorithms and online simulations.

Over the years, fault detection in transmission lines has become essential as it can improve the reliability of networks, lessen the loss in revenue, decrease power loss, and ensure that the service is restored quickly. There are many techniques used to locate faults in transmission lines, but because of the resources and equipment used to apply these techniques, it is deemed to be impractical and costly. Abu-Siada and Mir, suggests that online techniques be used to efficiently locate faults as no special equipment is required and no protective equipment needs to be employed for such applications.

Given the fast change and innovations in technology, the power demand continues to increase each day. Because of this, it is important to ensure that power is delivered, safely, efficiently, and at maximum. In a MATLAB simulation conducted by Rajput and Chaturvedi, it was proven that MATLAB simulation is an efficient software for carrying out algorithms to detect faults in transmission lines [16]. Amongst other simulations and techniques, online simulations were proven to be a good option as it is cost-efficient and can be easily carried out and manipulated.

\section{STATEMENT OF THE PROBLEM}

The researchers seek to understand the different fault behaviors of a three-phase transmission line. The researchers seek to simulate the possible outcomes of different types of faults. These types of faults are line-to-ground, line-to-line, double line-to-ground, and even triple line-to-ground. Understanding the patterns and behaviors of these types of faults will help in identifying the types of faults and how to fix address them in the real world.

Beginning a transmission line simulation in Matlab and Simulink can be complex when approached for the first time. The different control blocks and libraries needed are not immediately made clear. Furthermore, the proper settings and parameters need at least some explanation as existing documentation may not fully convey the functions of certain block parameters. Especially when considering their real-world equivalents.

Therefore, this study will provide an overview of how to create a transmission line system, and how to generate faults within that system to understand faults and their behaviors.

\section{SIGNIFICANCE OF THE STUDIES}

This study will be most relevant to those that seek to have a beginning overview of different types of recently proposed Transmission Line Fault Detection methods and also of Simulink Transmission line fault detection simulation. The study of transmission lines is important due to their growing use in the urbanization of different regions of the world [17].
For the overview of the different types of transmission line fault detection methods, the researchers will explore some newly proposed methods in the review of the related literature section. This basic exploration will provide readers with a basic understanding of how fault detection methods work. Therefore, this paper will be of use to readers seeking some understanding in this regard.

For the Simulink simulation, this study will explain the foundation blocks necessary for a transmission line simulation. This study will show a step by step methodology for a transmission line block setup, and analyze the output results generated by the software. This study will explore different types of faults in a three-phase transmission line. Thus providing even more usefulness to readers exploring information regarding three-phase transmission lines and their different behaviors under different faults. The transmission line simulation to be created in this study can also be used to create variant models utilizing different blocks to simulate different transmission line situations. As such, this study will be able to provide a good basis for more advanced studies related to transmission line fault detection simulation.

\section{DESCRIPTION OF THE SYSTEM}

To be able to successfully simulate faults in transmission lines, a transmission line circuit was developed with the use of MATLAB Simulink. The model was based on prior models studied. The circuit involves subsystems consisting of 5 cascaded blocks of the Three-Phase $\mathrm{Pi}$ Section Lines Subsystem with connection ports connected at each end. At the left side of the circuit, a Three-Phase source is connected which will act as a voltage source while another three-phase source with an offset of -30 degrees is added on the opposite end of the circuit to act as a load. Three-Phase V-I Measurement is connected to be able to measure voltage and current at each line. Also, a Three-Phase Fault is added into the system to be able to simulate faults in the system such that a stable system with no faults may be compared to one where faults are present. To ensure that the circuit will run at decreased simulation time obtaining much more accurate results, a graphical user interface is added into the circuit, a Powergui block which is set to have sample time to $3 \mathrm{e}-5$. The Simulink model can be observed in the figure below. More block parameter details will be discussed in the Methodology section. Figure 1 shows the transmission line system.

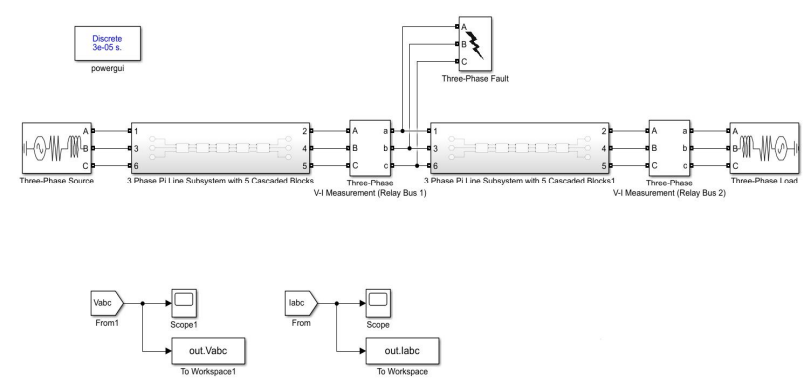

Figure 1: The Simulink block model of the Transmission Line System with a fault block connected. 
Aaron Don M. Africa et al., International Journal of Emerging Trends in Engineering Research, 8(9), September 2020, 5434 - 5444

\section{METHODOLOGY}

Figure 2 shows the flowchart of the methodology.

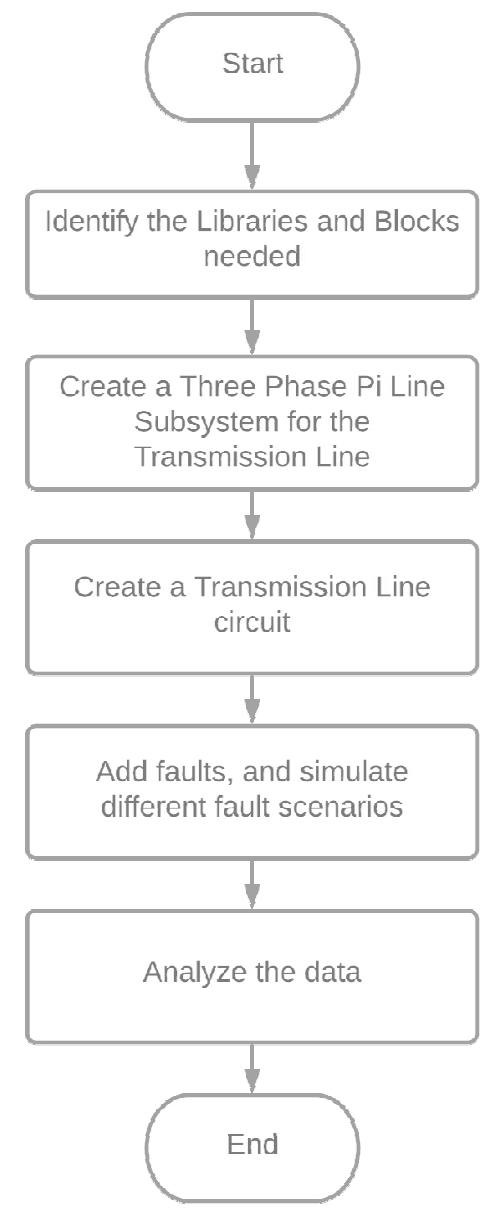

Figure 2: The Flowchart for the Methodology Process

The researchers began by constructing a transmission line block system in Simulink. The specific blocks used were the following:

1. Three Phase Pi Section Line

2. Connection Port

3. Three-Phase Fault

4. Three-Phase V-I Measurement

5. Three-Phase Source

6. Powergui

7. Scope

8. From

9. To Workspace

To create a Transmission Line system, the researchers began by creating a Three-Phase Pi Line subsystem. To create the Three Phase Pi Line subsystem, five Three Phase Pi Line blocks and six connection port blocks must be brought to the workspace. As of Matlab R2020, block should be located in Simscape > Electrical > Specialized Power Systems
$>$ Fundamental Blocks > Elements. Figures 3 to 16 shows the diagrams and parameters used.

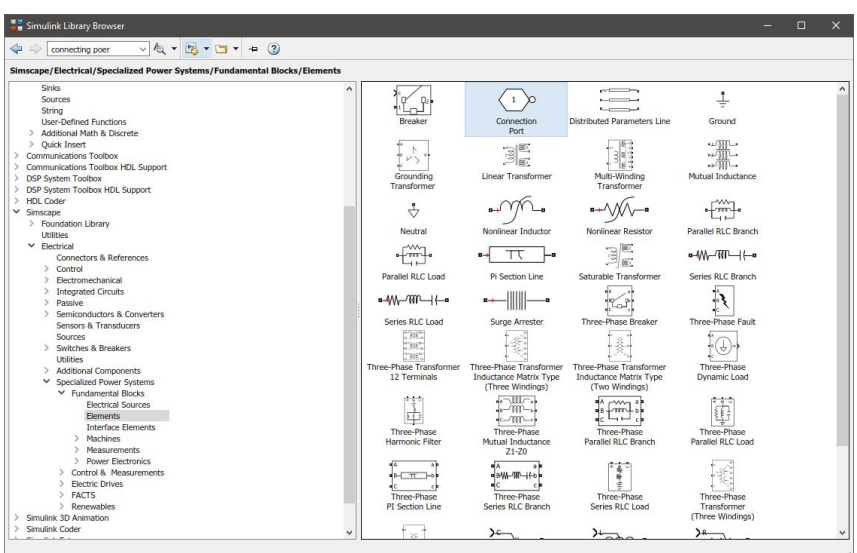

Figure 3: The Library Browser at the location of the Three-Phase Pi Line block and the Connection Port block.
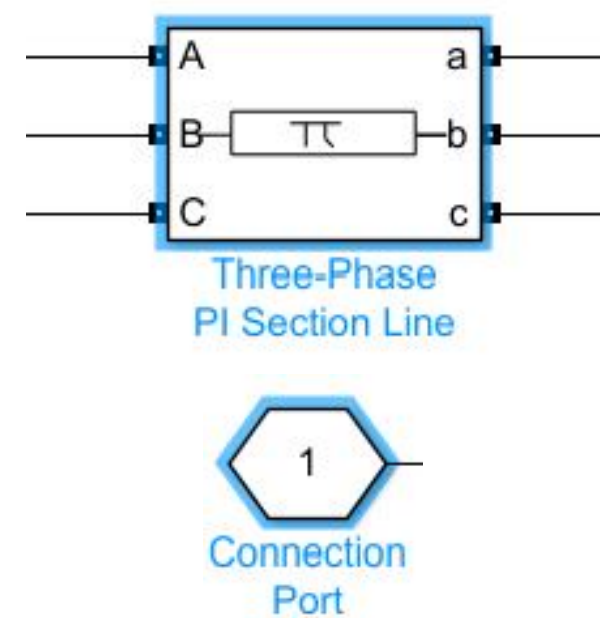

Figure 4: The Three-Phase Pi Line block and the Connection Port block.

The researchers left the Three Phase Pi Section Line blocks at their default settings as part of the theoretical assumptions of an ideal transmission line system. The blocks were then connected in the manner shown below.

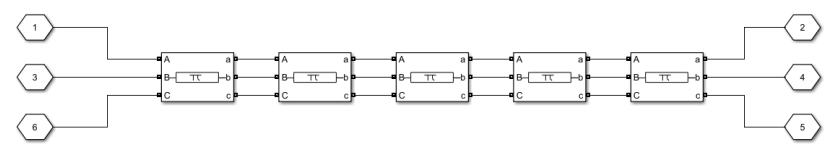

Figure 5: A Three-Phase Pi Section Line setup

The researchers then create a subsystem block out of this setup by selecting everything and pressing Ctrl+G. This resulted in the subsystem block shown below. 


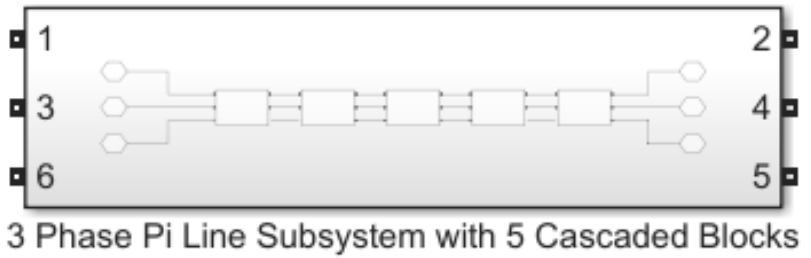

Figure 6: The Three-Phase Pi Section Line subsystem block

The researchers then generated the blocks needed to create the Transmission Line System.
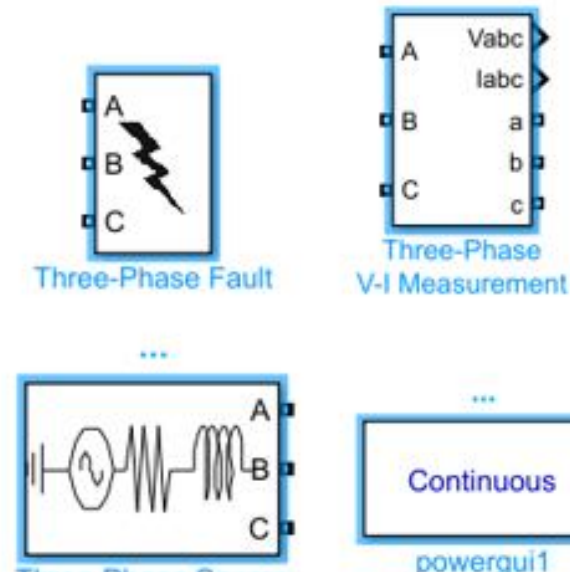

Three-Phase Source
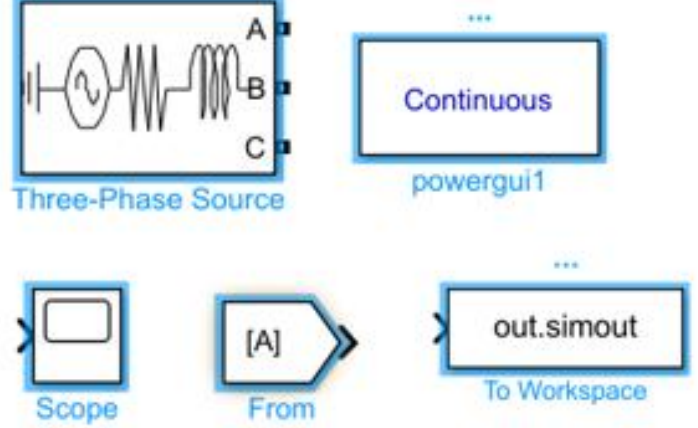

Figure 7: The blocks needed to create the Transmission Line System.

The blocks were then connected in the manner shown below.

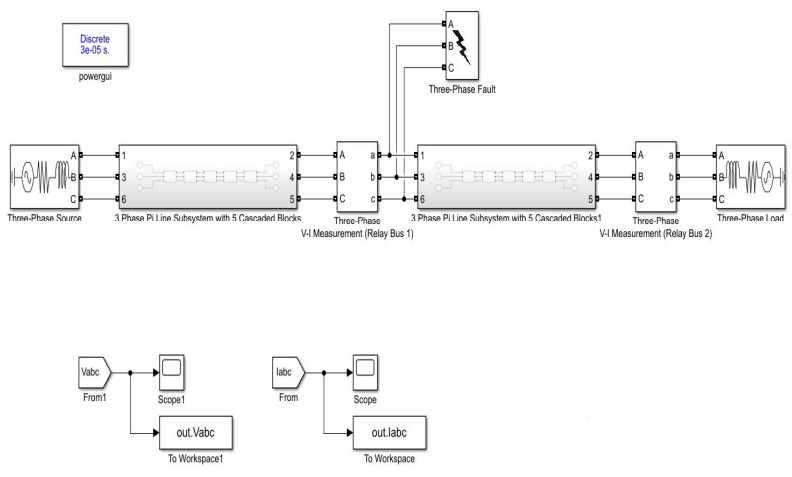

Figure 8: The Transmission Line system
The parameters used for each block can be found below.

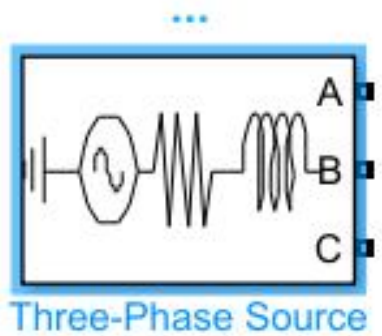

Figure 9: Three phase source system

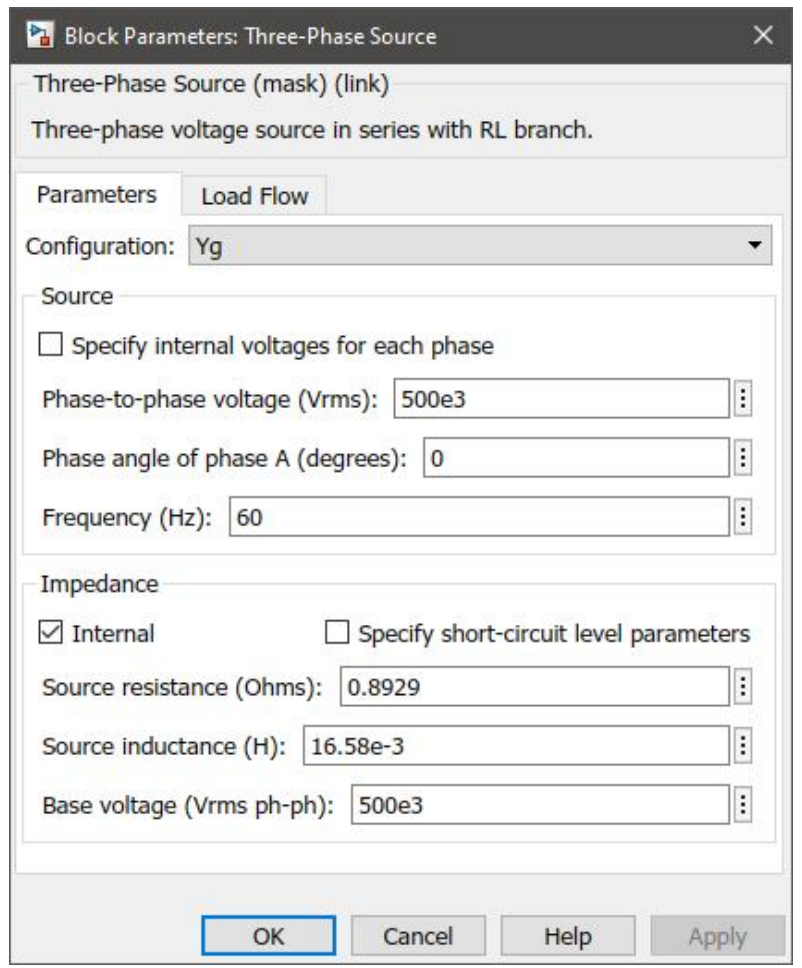

Figure 10: The Three-Phase Source block.

The Three-Phase Source block will act as the voltage source of the transmission line circuit.

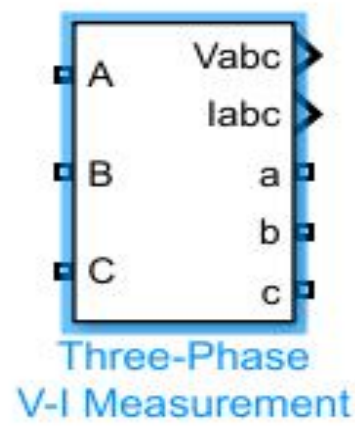

Figure 11: Three Phase VI measurement 
Aaron Don M. Africa et al., International Journal of Emerging Trends in Engineering Research, 8(9), September 2020, 5434 - 5444

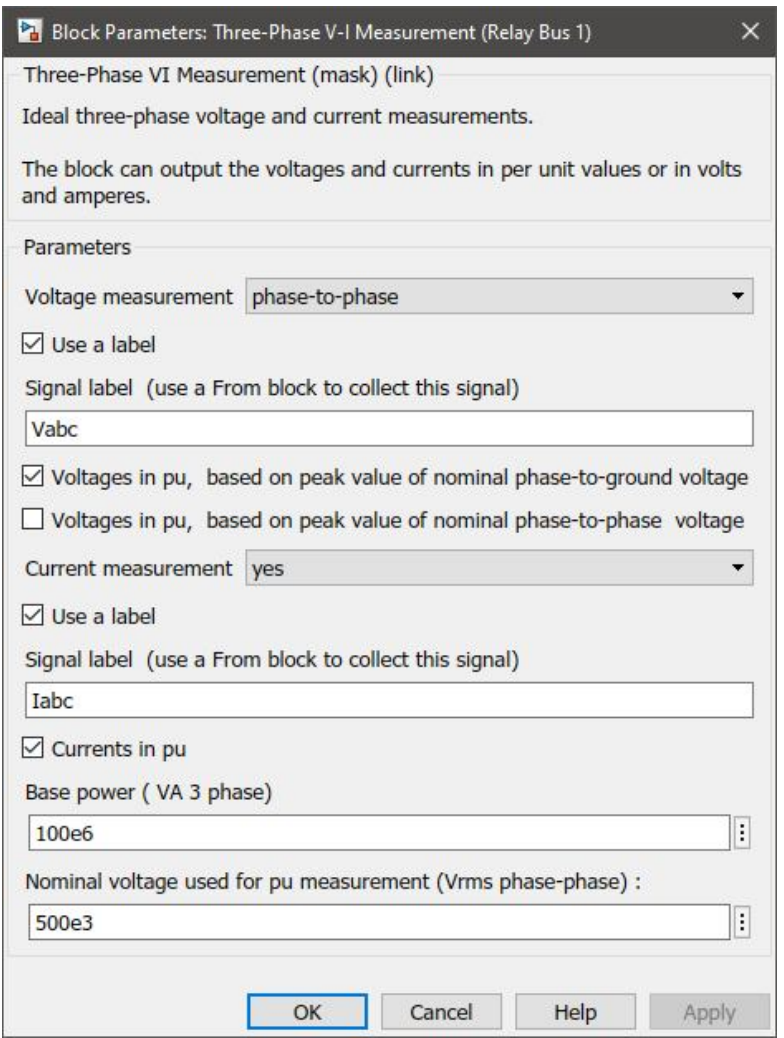

Figure 12: The Three-Phase V-I Measurement block.

The Voltage (Vabc) and Current (Iabc) measurements will be taken on this block.

\section{Block Parameters: Three-Phase V-I Measurement (Relay Bus 2)}

Three-Phase VI Measurement (mask) (link)

Ideal three-phase voltage and current measurements.

The block can output the voltages and currents in per unit values or in volts and amperes.

\section{Parameters}

Voltage measurement no

Current measurement no

\section{OK}

\section{Cancel}

Help

Apply

Figure 13: Three-Phase V-I Measurement block.

No measurements were performed on this second Three-Phase V-I Measurement block. This block will act as a relay bus for the circuit.

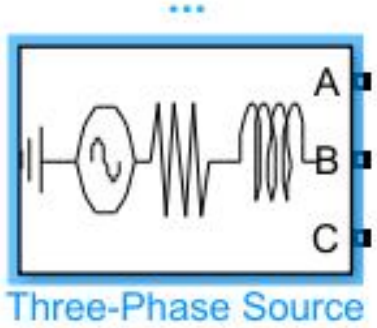

Figure 14: Three Phase Source

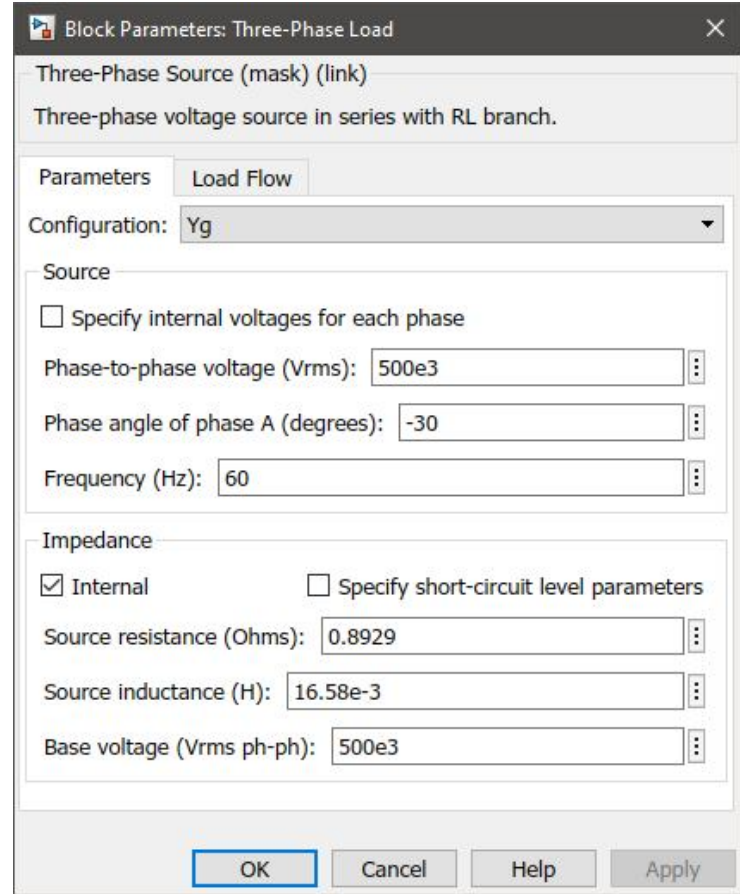

Figure 15: Phase angle set to -30 o to act as a load

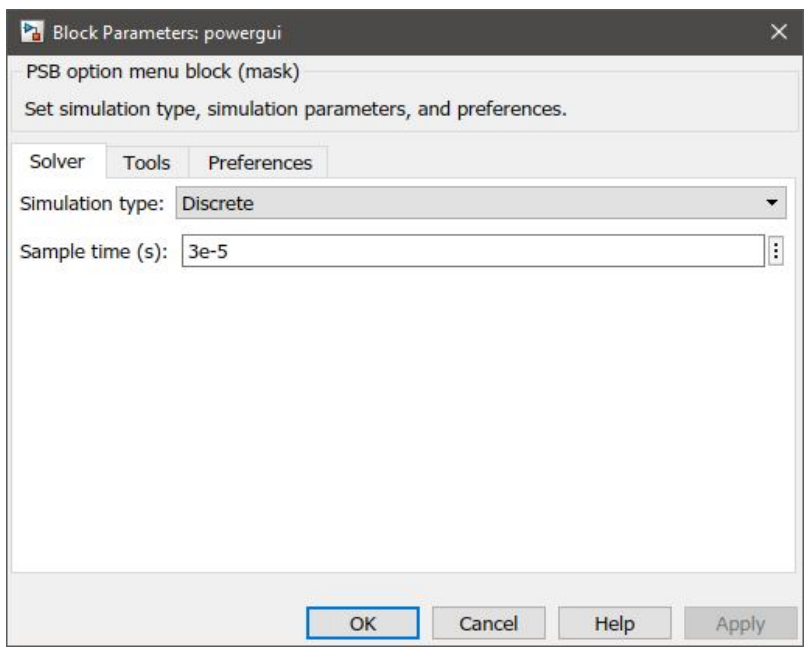

Figure 16: The Powergui block

Set the Powergui block to Discrete-time to decrease simulation computation time. Set sample time to $3 e-5$. This is an arbitrary value. Lower values will yield more accurate results at the cost of longer computation time. 
Aaron Don M. Africa et al., International Journal of Emerging Trends in Engineering Research, 8(9), September 2020, 5434 - 5444

Before conducting any simulations, the Fault block had no faults enabled.

\section{REVIEW OF RELATED LITERATURE}

In a review on fault location method of distribution power [18], Mirzaei et al. introduce that there have already been several fundamental approaches as to how to detect faults in transmission lines. One of which is the impedance-based method. In this type of method, an impedance-based method is used to be able to approximate the distance of fault between the primary distribution bus and the fault location. In this type of application, mathematical equations are used to be able to obtain an estimated fault location employing using the obtained voltage and current values. In this type of method, voltage and current values can be obtained at one end or two ends in this case this is called the single-ended and double-ended method respectively. Although amongst all techniques the impedance-based method is the simplest this indicates that there are some setbacks such as multi-estimation claiming this method to be precise but not accurate due to estimations occurring over a possible series of faults. Although some concepts from the impedance-based methods are used, the traveling wave method is a much more reliable approach to detecting fault precisely and accurately.

Faults can occur in electric power systems which supply energy to three main structures vital to everyday functions in society. In a review on fault location techniques in the electrical power system, Goh et al. [19], indicates that faults in electric power systems can be caused by several factors such as nature, human and equipment. With this, fault location is of significance to be able to ensure that the system is continuously running, loss in revenue is minimized and hazards to the environment and equipment. It states that a traveling-based method for determining faults in transmission lines are much more advantageous as the load variance, series capacitor bank, and high grounding resistance will not affect the process of fault location. Although this is a much more efficient method, it may also be much more expensive due to the devices needed for this approach.

One important factor in the study is to be able to simulate an efficient model for a three-phase power system network. Without a working simulated environment, no algorithm will be deemed effective in this study. The MATLAB based Simulation model for three phases Power System Network Tharani et al [20], proves that MATLAB software is convenient and reliable for analysis and simulation of three-phase faults in transmission lines.

L-G fault, LL-G fault, and LLL-G fault were tested in a novel scheme of transmission line faults analysis and detection by using MATLAB Simulation utilizing the Simulink and the sim-power toolbox. Karekar, Thakur, and Manju [21] indicate that the implementation of MATLAB software in this study is efficient. This study comprises a system with $33 \mathrm{Kv}$ generators, three-phase simulators, and distributed parameter lines. In this model, the role of the three-phase simulators is to be able to simulate faults at the mid position while the distributed parameter lines represent the faults on the transmission line.

In a study done by Zhang, Tai, Wu, Fan, Zheng, and Huang, it was concluded that the one possible way for a fault to be located in transmission lines is by measuring the current at the end of the line without taking into account the reflected current waves present[22]. 3 methods of fault location were done such as locating faults without considering reflected waves, locating faults in line with considering reflected waves, and locating faults in mixed lines. With the three methods conducted, it was proven that locating faults in mixed lines is most efficient no matter how parameters are set.

Due to the power system's complexity, analysis of the system to ensure the maintenance continues to be reliable becomes more and more difficult. Many industries can not afford to continuously depend on a system of poor efficiency and reliability. As transmission lines may be positioned in obscure areas, proper techniques must be used to ensure that the stability of the transmission lines can be detected to avoid continuity in power supplies [23]. In a MATLAB-Based GUI Development for the Detection and Localization of Faults in Transmission Line conducted by Lala, Karmakar, and Singh, MATLAB-based simulation with the utilization of graphical user interface or GUI has been proven to obtain a better level of accuracy and precision in terms of obtaining results[24].

Over the years, it has been analyzed by Gowrishankar, Nagaveni, and Balakrishnan that the most common type of fault occurring in a transmission line is a single line to ground fault ranging from $70-80 \%$, while the second most prevalent is the Line-to-Line ground fault ranging from 10-17\%. Followed by line-to-line faults ranging from $8-10 \%$ and the least common of all faults is a three-phase fault with an average of 3\% [25]. Through this study, it can be determined that MATLAB simulation is an efficient mean to be able to simulate three-phase current signal on transmission lines to be able to detect faults, with further studies utilizing ANN this study deems that integrating online algorithms with the utilization of Artificial Neural Network in detecting faults prove promising results.

In a study conducted by Devi, Swarnkar, Ola, and Mahela, transmission lines faults were tested with non-linear and linear loads with the use of traveling-wave or high-frequency transients[26]. By testing different loads, power systems may be optimized enabling detecting with dynamic loads. This study utilizes a system containing a three-phase source and three-phase loads. While varying loads, tests were also performed with different types of faults such as phase to ground, double line fault, double line to ground fault, and three-phase fault. It was concluded that in linear loads, high voltages were observed where faults occur while in dynamic loads, voltages vary depending on the type of fault occurring. Through this study, further understanding of the behavior of 
faults in various loads enables future studies to create algorithms and models to address these errors.

In a Matlab Simulation-Based Study of Various Types of Faults Occurring in the Transmission Lines, Boora et al.[27] indicates that MATLAB is an efficient software for simulating transmission lines due to the presence of graphical methods. Another advantage is that the language used in MATLAB is straight to the point and simple ensuring that modification and composition of algorithms can be executed easily in an integrated environment. In this specific study, the model comprises variables such as three-phase transformers, loads, and sources that are used to be able to simulate various faults. In this case, several faults were tested separately such as the single line to ground fault, line to line fault, and double line to ground faults. In this study, an essential component used is the circuit breaker as this was added and removed to the system to simulate a transmission line with fault and without fault. This paper concluded that MATLAB is an efficient software for simulating faults in transmission lines. The versatility of MATLAB and Simulink for Power System Studies can also be observed in Ikhide, et al.'s study on high voltage DC transmission systems [28]. These types of systems are different from the three-phase systems typically associated with transmission lines. Thus, MATLAB and Simulink are a viable choice for power systems studies and simulations.

MATLAB's versatility can be observed in the different types of transmission line fault studies conducted throughout the years. Poste, et al.'s 2016 study [29] explored the voltage sag phenomena that can occur in three-phase systems with faults. To conduct this study, they simulated different voltage sag models in MATLAB and Simulink under different three-phase fault conditions. Another study by Devi, et al. [30] again used MATLAB to simulate transmission line faults under different load conditions. MATLAB and Simulink enable studies such as these to promote further evolution on transmission line fault detection methods.

\section{THEORETICAL CONSIDERATIONS}

In terms of theoretical considerations, this study will assume a few ideal scenarios for the transmission line system. These ideal scenarios will be based on the parameters adjustable within the blocks used in the Simulink Transmission Line simulation. As such, the study assumes that the transmission line behaviors observed within the study will apply to real-world transmission lines with some slight differences, as real-world systems may have more variables to consider.

The researchers will also assume that discrete-time simulations will provide more-or-less the same outcomes as continuous-time simulations. Discrete-time simulations will be used to reduce simulation times.

\section{DATA AND RESULTS}

Without any faults enabled, the scopes show the following results. Figure 17 to 28 shows the simulation output.

Throck Parameters: Three-Phase Fault
Three-Phase Fault (mask) (link)
Implements a fault (short-circuit) between any phase and the
ground. When the external switching time mode is selected, a
Simulink logical signal is used to control the fault operation.
Parameters
Initial status: 0
Fault between:
\[ \text { Phase A Phase B } \]
Switching times (s): [1/60 $5 / 60]$
Fault resistance Ron (Ohm): 0.001
Ground resistance Rg (Ohm): 0.01
Snubber resistance Rs (Ohm): 1 Phase C
Snubber capacitance Cs (F): inf
Measurements None
\[ \text { OK } \]

Figure 17: No faults enabled: Three-Phase Fault Block Parameters

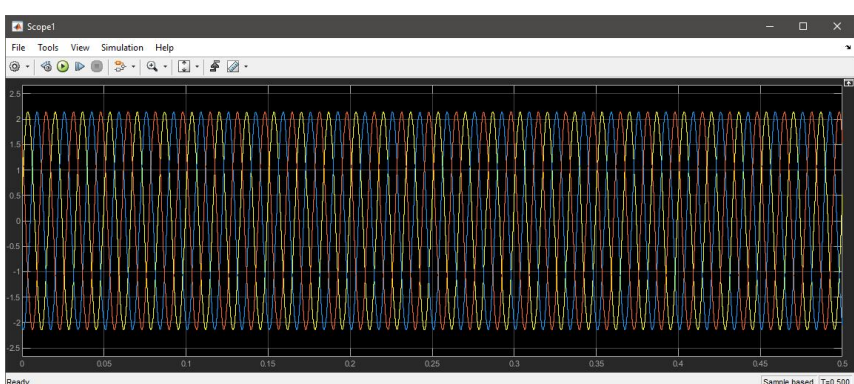

Figure 18: Balanced System: Voltage Scope

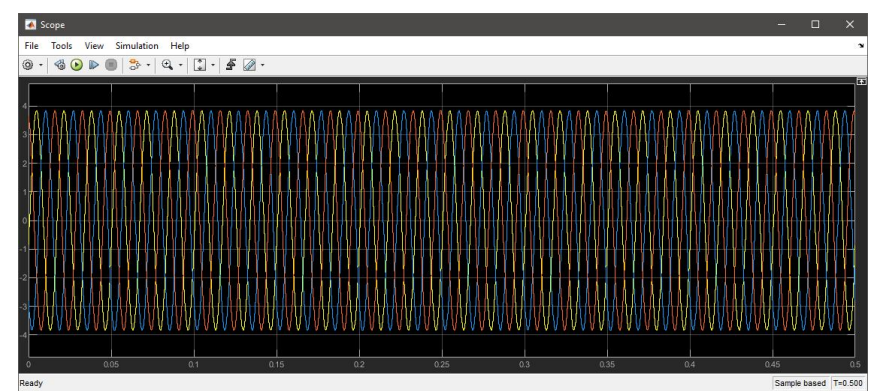

Figure 19: Balance System: Current Scope

\section{The line to Ground Faults}

If all faults on all phases (A, B, C to Ground) are turned $\mathrm{ON}$, the scopes show the following: 


Three-Phase Fault (mask) (link)
Implements a fault (short-circuit) between any phase and the
ground. When the external switching time mode is selected, a
Simulink logical signal is used to control the fault operation.
Parameters
Initial status: 0
Fault between:
$\square$ Phase A $\square$ Phase B
Switching times (s): [1/60 $5 / 60]$
Fault resistance Ron (Ohm): 0.001
Ground resistance Rg (Ohm): 0.01
Snubber resistance Rs (Ohm): 1 C6
Snubber capacitance Cs (F): inf
Measurements None
\[ \text { OK } \]

Figure 20: Triple Line Fault: Three-Phase Fault Block Parameters

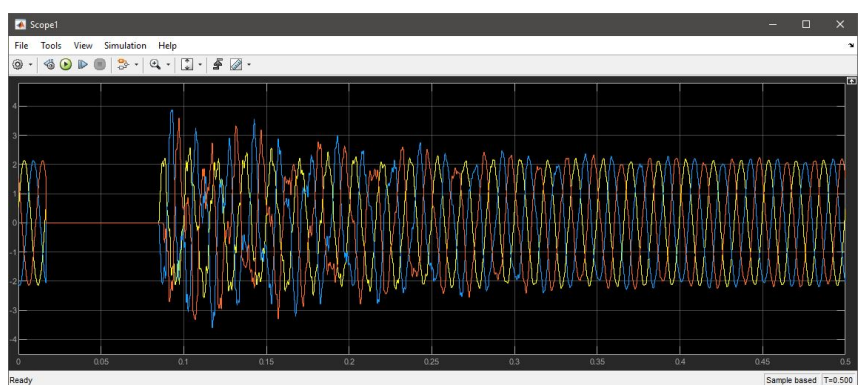

Figure 21: Triple Line Fault: Voltage Scope

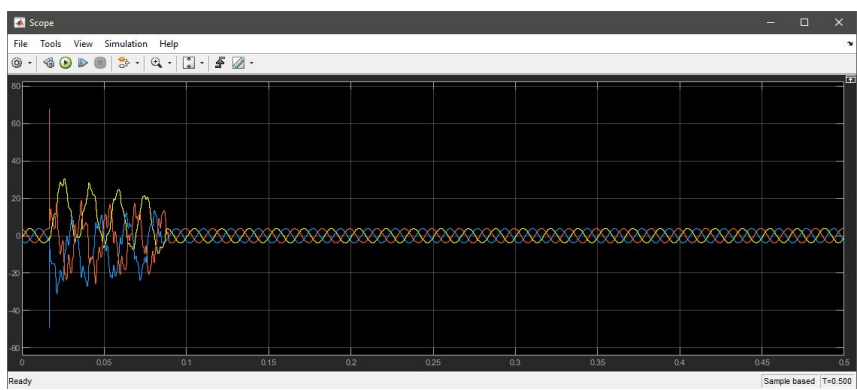

Figure 22: Triple Line Fault: Current Scope

A to Ground:

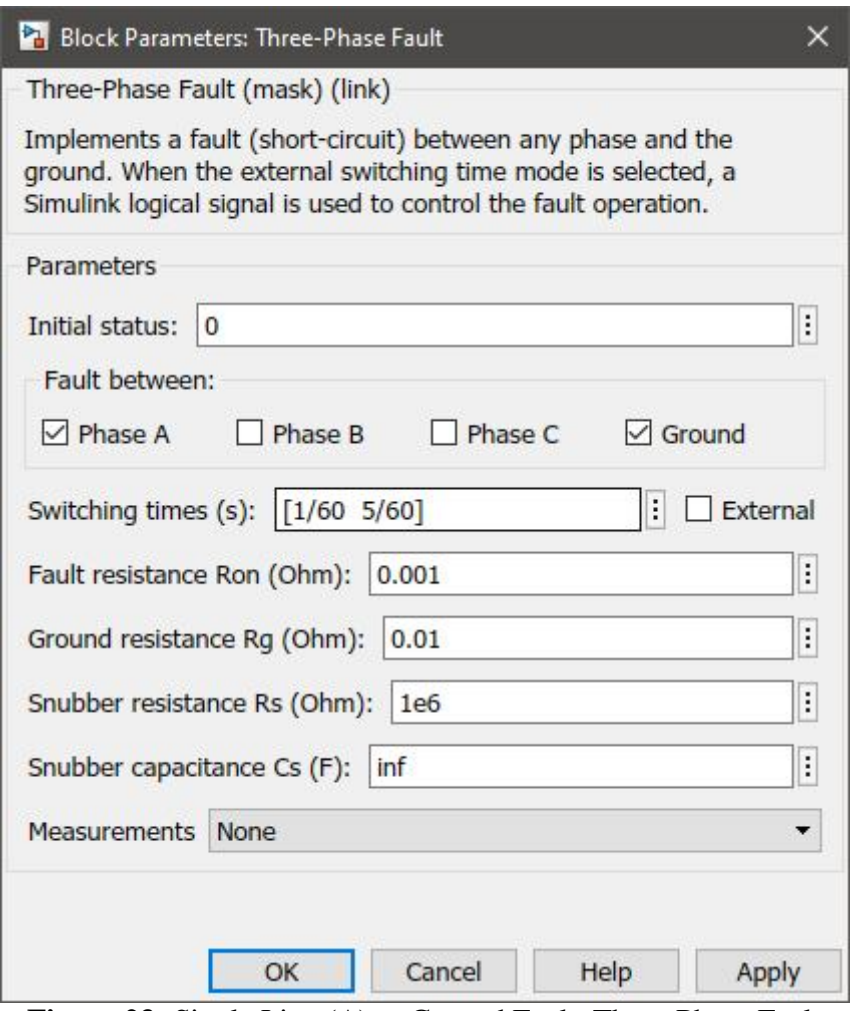

Figure 23: Single Line (A) to Ground Fault: Three-Phase Fault Block Parameters

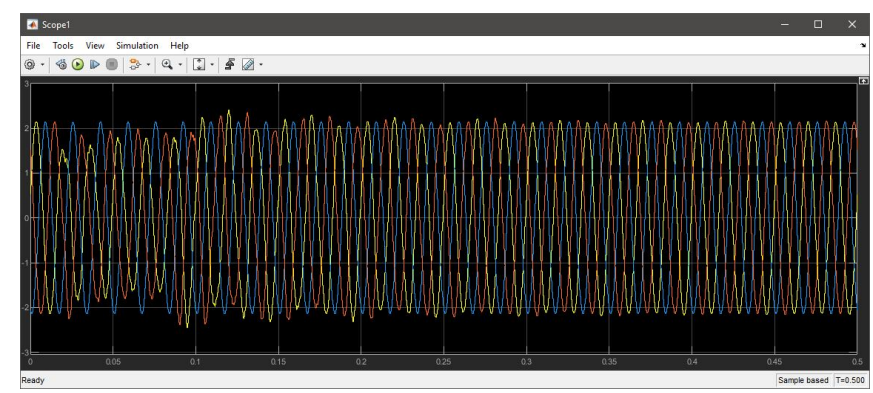

Figure 24: Single Line (A) to Ground Fault: Voltage Scope

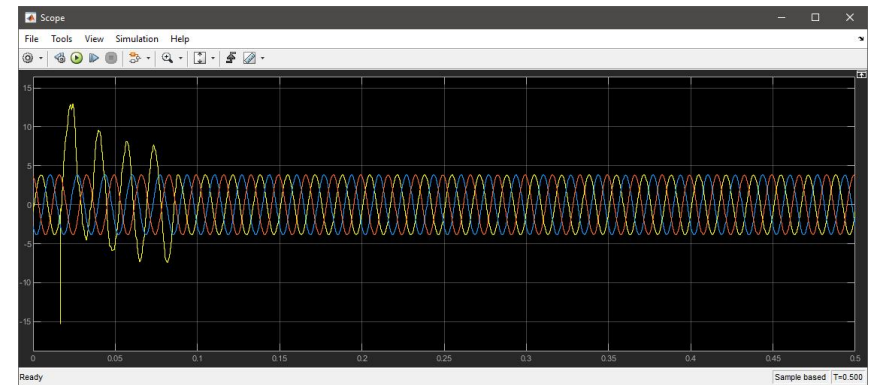

Figure 25: Single Line (A) to Ground Fault: Current Scope

B to Ground 


Three-Phase Fault (mask) (link)
Implements a fault (short-circuit) between any phase and the
ground. When the external switching time mode is selected, a
Simulink logical signal is used to control the fault operation.
Parameters
Initial status: 0
Fault between:
$\square$ Phase A $\square$ Phase B
Switching times (s): [1/60 $5 / 60]$
Fault resistance Ron (Ohm): 0.001
Ground resistance Rg (Ohm): 0.01
Snubber resistance Rs (Ohm): 1 Phase C
Snubber capacitance Cs (F): inf
Measurements None
\[ \text { OK } \]

Figure 26: Single Line (B) to Ground Fault: Three-Phase Fault Block Parameters

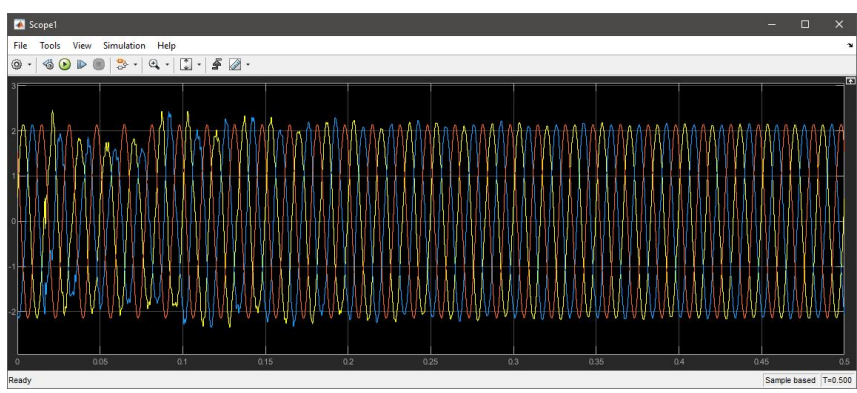

Figure 27: Single Line (B) to Ground Fault: Voltage Scope

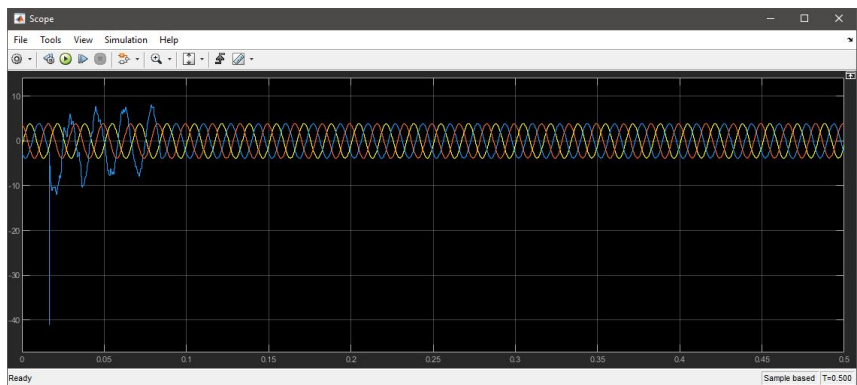

Figure 28: Single Line (B) to Ground Fault: Current Scope

\section{ANALYSIS OF DATA}

In the preceding simulations, a single line to ground fault occurs. The scope shows that the voltage of the phase connected to the ground fluctuates while the voltages of the other phases are slightly disturbed. Since a fault in only one phase is present, we can see that the current where the fault occurs suddenly peaks at approximately 0.01 seconds in the simulation and destabilizes while the other phase currents continue to stay stable throughout the simulation.

This occurs when A and B, B and C or A and C are connected to ground. The scopes show that the voltages experience heavy fluctuations at the period where the fault occurs. While the currents with faults experience a sudden peak at the beginning of the fault and continue to experience fluctuations throughout the fault. The current of the phase without any faults remains stable.

Based on the results, we can see that the fault occurred at approximately 0.01 seconds. At this certain time, the voltage drops to 0 as seen in the results of Vabc while the current in Iabc suddenly peaks. After the period is detected at $0.15 \mathrm{~s}$, the voltage and current now becomes stable and continue to stabilize. For the Line to line faults such as those found in Figures 9.25 and beyond, the behavior is comparable to the multi-line to ground faults.

\section{CONCLUSION}

Transmission Line simulations in MATLAB and Simulink prove to be quite capable once the researchers become familiar with the various blocks and functions available in the two programs [31]. This study first conducted explored various recently proposed transmission line fault detection techniques envisioned by other studies. These studied showed how various approaches and algorithms can be used to assess transmission line faults [32]. This study then proceeded with an explanation of how the researchers created a base Transmission Line simulation model in Simulink. Each block and its parameters were explained. The researchers explained how to create a cascaded Three-phase Pi Line subsystem within Simulink, and then proceeded to explain how to create the full Transmission Line circuit. The integral block for the Three-phase transmission line fault detection simulation was the Three-Phase fault block. The block was connected across the circuit with one connection on each phase line. With this, the researchers simulated various fault scenarios. These scenarios include a transmission line without any faults, line to ground faults, multi-line to ground faults, line to line faults, and multi-line faults. The different faults displayed different outcomes with the voltage and current readouts. What could generally be seen was that the faults would cause the voltage to destabilize and generally lower in value, while the current would destabilize and abruptly increase in value. These turbulences would undoubtedly damage a real-world transmission line circuit [33]. As such, this study has shown how transmission line faults can be simulated within MATLAB and Simulink. The simulations were conducted in discrete time to reduce simulation computation time. The researchers assumed that there would be no significant difference between continuous-time and discrete-time simulation for the study. The model created in this study can be used in subsequent studies to further simulate various transmission line faults. As such, transmission line fault detection simulation has been proven to be very much doable within MATLAB and Simulink. 
Aaron Don M. Africa et al., International Journal of Emerging Trends in Engineering Research, 8(9), September 2020, 5434 - 5444

\section{RECOMMENDATIONS}

Through the experiment, it was proven that the utilization of MATLAB Simulink in simulating faults in transmission lines is efficient and successful. This study included results in simulating different faults occurring in transmission lines namely the three-phase fault, single line to ground fault, line to line fault, and double line to ground fault. The relationship of faults in transmission lines was observed by measuring the current and voltage in the system. With the use of the scope, the effect of each fault was identified throughout the experiment. Through the simulation it is clear that the three-phase fault block is successfully used; this was proven when it was added to a healthy system and removing it to be able to compare results of different simulations.

As different types of faults have been simulated throughout this study, integrating other algorithms to detect faults can be done for further studies. This study could be improved, by integrating algorithms to detect all kinds of faults in one simulation without changing any parameters. This can ensure that in real-life applications, at any given time and location, any fault may be detected immediately without the necessary need of using multiple devices or special equipment to detect these faults. Based on research, the group suggests that Artificial Neural Networks or ANN be used to integrate with this study. With the use of ANN, an intelligent model can be designed such that the system can recognize multiple faults over a series of simulations ensuring that different faults occurring at any time can be detected by the system. Moreover, this study could be improved by testing it on various dynamic loads, such as linear and non-linear loads to mold the study for real-life applications since loads are not constantly linear nor are they the same in every situation and application.

\section{REFERENCES}

[1] A. Abu-Siada and S. Mir, "A new on-line technique to identify fault location within long transmission lines", Engineering Failure Analysis, vol. 105, pp. 52-64, 2019.

[2] M. Parsi, P. Crossley, P.Dragotti and D. Cole, "Wavelet based fault location on power transmission lines using real-world travelling wave data". Electric Power Systems Research, vol. 186, 2020.

[3] M. Ghazizadeh-Ahsaee, "Time-domain based fault location for series compensated transmission lines without requiring fault type". Electric Power Systems Research, 181, 2019.

[4] E. Akher et al., "Fault Detection and Classification of Shunt Compensated Transmission Line Using Discrete Wavelet Transform and Naive Bayes Classifier," Energies, vol .13, p. 243, 2020.

[5] M. Choudhury and A. Ganguly, "Transmission line fault classification using discrete wavelet transform," International Conference on Energy, Power and Environment: Towards Sustainable Growth (ICEPE), Shillong,pp. 1-5, 2015.
[6] A. Abu-Siada and S. Mir, "A new on-line technique to identify fault location within long transmission lines,"Engineering Failure Analysis, vol. 105, pp. 52-64, 2019.

[7] A. Sharique, A.Sharma, Deepika and P. Rajput, "Fault Detection in Transmission line Using MATLAB," 2nd National Conference in Intelligent Computing \& Communications, ISBN: 9788175157538

[8] A.B. Alizadeh, M. Khederzadeh and R. Razzaghi, "Fault detection during power swing in thyristor-controlled series capacitor-compensated transmission lines," Electric Power Systems Research, vol. 187, 2020.

[9] A. Ghorbani, H. Mehrjerdi, , H. Heydari and S. Ghanimati, "A pilot protection algorithm for TCSC compensated transmission line with accurate fault location capability," International Journal of Electrical Power and Energy Systems, vol. 122, 2020.

[10]I. Ibrahim, "Fault detection and location of power transmission lines using intelligent distance relay," International Journal of Power Electronics and Drive Systems. Vol. 11, pp. 726-734.

[11]E.P. Thwe and M.M. Oo, "Fault Detection and Classification for Transmission Line Protection System Using Artificial Neural Network," Journal of Electrical and Electronic Engineering. Vol. 4, No. 5, 2016, pp. 89-96, 2016.

[12] A. Aggarwal, H. Malik and R. Sharma, "Feature extraction using EMD and classification through Probabilistic Neural Network for fault diagnosis of transmission line," IEEE 1st International Conference on Power Electronics, Intelligent Control and Energy Systems (ICPEICES), Delhi, pp. 1-6, 2016.

[13] S.R. Fahim, Y. Sarker, S. K. Sarker, M. R.I. Sheikh, and S. K. Das, "Self-attention convolutional neural network with time series imaging based feature extraction for transmission line fault detection and classification," Electric Power Systems Research, vol. 187,2020

[14] X. Huang, E. Shang, J. Xue, H. Ding and P. Li, "A Multi-feature Fusion-based Deep Learning for Insulator Image Identification and Fault Detection," IEEE 4th Information Technology, Networking, Electronic and Automation Control Conference (ITNEC), Chongqing, China, pp. 1957-1960, 2020.

[15]M. Salehi, et al. "Determining minimum number and placement of fault detectors in transmission network for fault location observability,"International Journal of Electrical Power and Energy Systems, vol. 124, 2020.

[16] S. Rajput and K.T. Chaturvedi, "Transmission Line Fault Analysis by Using Matlab Simulation," IJREE International Journal of Research in Electrical Engineering, vol. 3, no. 4, 2016.

[17] K. Sun et al., "A Cable Fault Identification and Location Method Based on HEM," 5th Asia Conference on Power and Electrical Engineering (ACPEE), Chengdu, China, 2020, pp. 1657-1661, 2020.

[18] M. Mirazei, M.Z. Ab Kaidr, E. Moazami and H. Hizam, "Review of fault location methods for distribution power 
Aaron Don M. Africa et al., International Journal of Emerging Trends in Engineering Research, 8(9), September 2020, 5434 - 5444

system," Australian Journal of Basic and Applied Sciences, vol. 3, pp. 2670-2676.

[19] H.H Goh et al., "Fault Location Techniques in Electrical Power System: A Review," Indonesian Journal of Electrical Engineering and Computer Science, Vol. 8, No. 1, pp. 206 - 212, 2017.

[20]C. Tharani, M. Nandhini, R. Sundar, and K. Nithiyananthan, "MATLAB based Simulations model for three phases Power System Network," International Journal for Research in Applied Science \& Engineering Technology (IJRASET), vol. 4, p. 502-509, 2016.

[21]S. Karekar, V. Thakur and M., "A Novel Scheme of Transmission Line Faults Analysis and Detection by Using MATLAB Simulation," International Journal of Engineering Research and General Science, Vol. 4, No. $1,2016$.

[22]X. Zhang, N. Tai, P. Wu, C. Fan, X. Zheng and W. Huang, "A New Theory for Locating Line Fault in Power System: Theoretical Part," in IEEE Access, vol. 7, pp. 91337-91346, 2019.

[23] X. D. Wang, X. Gao, Y. M. Liu and Y. W. Wang, "WRC-SDT Based On-Line Detection Method for Offshore Wind Farm Transmission Line," in IEEE Access, vol. 8, pp. 53547-53560, 2020.

[24] H. Lala, S. Karmakar and A. K. Singh, "MATLAB-Based GUI Development for the Detection and Localization of Faults in Transmission Line," IEEE Region 10 Symposium (TENSYMP), Kolkata, India, pp. 654-659, 2019.

[25] M. Gowrishankar, P. Nagaveni and P. Balakrishnan, "Transmission Line Fault Detection and Classification Using Discrete Wavelet Transform and Artificial Neural Network," Middle East Journal of Scientific Research, vol. 24, pp. 1112-1121.

[26] S. Devi, N. Swarnkar, S. Ola and O. Maheka, "Analysis of transmission line faults with linear and dynamic loads" pp. 99-103, 2016.

[27]D. Boora, "Matlab Simulation Based Study of Various Types of Faults Occurring in the Transmission Lines," International Journal of Engineering Research, vol. 8.

[28] M. Ikhide, S. Tennakoon, A. Griffiths, S. Subramanian and H. Ha, "Fault detection in Multi-Terminal Modular Multilevel Converter (MMC) based High Voltage DC (HVDC) transmission system," 50th International Universities Power Engineering Conference (UPEC), Stoke on Trent, pp. 1-6, 2015.

[29] A. S. Poste, B. T. Deshmukh and B. E. Kushare, "Detection, classification \& characterisation of voltage sag," 2016 International Conference on Electrical, Electronics, and Optimization Techniques (ICEEOT), Chennai, pp.232-237, 2016.

[30] S. Devi, N. K. Swarnkar, S. R. Ola and O. P. Mahela, "Analysis of transmission line faults with linear and dynamic loads," Conference on Advances in Signal Processing (CASP), Pune,pp. 99-103, 2016.

[31] Matlab.

https://www.mathworks.com/products/matlab.html.

2020 .
[32] A. Africa, J. Chua and P. Yao, "Design of an automatic voltage regulator using MATLAB for real-time ECG signal transmission monitoring applications," International Journal of Emerging Trends in Engineering Research, vol. 8, no. 7, pp. 3063-3070, 2020.

[33] A. Salem and T. Alhmiedat, "Energy-efficient clustering wsn system for environment monitoring applications," International Journal of Emerging Trends in Engineering Research, vol. 8, no. 5, pp. 2126-2132, 2020. 